\title{
Roles of Ecosystems in Greenhouse Gas Emission and Haze Reduction in China
}

\author{
Xiang Niu ${ }^{1,2,3}$, Bing Wang ${ }^{1,2,3 *}$, Wenjun Wei ${ }^{1,4 * *}$ \\ ${ }^{1}$ Research Institute of Forest Ecology, Environment and Protection, Chinese Academy of Forestry, \\ Beijing 100091, Beijing, China \\ ${ }^{2}$ Key Laboratory of Forest Ecology and Environment,State Forestry Administration, \\ Beijing 100091, Beijing, China \\ ${ }^{3}$ Beijing Collaborative Innovation Center for Eco-Environmental Improvement with Forestry and Fruit Trees, \\ Beijing 100091, Beijing, China \\ ${ }^{4}$ Liaoning Academy of Forestry, Shenyang 110032, Liaoning, China
}

Received: 7 September 2016

Accepted: 30 December 2016

\begin{abstract}
The haze satellite map produced by NASA in 2013 showed a "Gray Great Wall" in the sky from Beijing to Hong Kong, indicating serious air pollution in China. The air pollutants and greenhouse gases can be reduced through engineering measures known as industrial gas emission and haze reduction (GGE\&H reduction), as well as through green GGE\&H reduction by ecosystems such as forests and wetlands that play significant roles in carbon sequestration and atmospheric environmental purification of air, soil, and water. Compared with the industrial GGE\&H reduction, the green GGE\&H reduction is lower in investment and operational cost, but offers more ecological benefits and therefore is more economically feasible. In this review the roles of green GGE\&H reduction are summarized and its future potential is highlighted. The possible approaches to enhance the capability of green GGE\&H reduction in China are discussed.
\end{abstract}

Keywords: air pollution, industrial and green GGE\&H reduction

\section{Introduction}

The fifth assessment report of the Intergovernmental Panel on Climate Change (IPCC) indicates the causal relationships between human activities and global climate change since industrialization, and the imminent need for climate change mitigation and greenhouse gas emission reduction [1]. Besides rising $\mathrm{CO}_{2}$ and temperatures, industrialization also causes air pollution, which has

*e-mail: wangbingcfern@163.com

**e-mail:wwj0318@126.com resulted in several public events (e.g., the London Smog Disasters of 1952 and gray sky in China) and has drawn extensive attention [2-4]. Pollution increases the incidence and mortality of cardiovascular and respiratory diseases, especially after exposure to ultrafine (nano) particles [5].

The relationship between climate change and air pollution needs to be further examined; however, due to similar sources and control measures, many countries and international organizations have begun to integrate control measures for the two by-products of industrialization. The United Nations Environment Program (UNEP) has established the Climate and Clean Air Coalition to coordinate member states to jointly cope with climate change and air pollution. 
Greenhouse gas emissions and haze can be reduced through direct and indirect approaches [6-9]. The direct greenhouse gas emission and haze $(\mathrm{GGE} \& \mathrm{H})$ reduction involves engineering measures to control the releases of greenhouse gases and pollutants, which is also known as industrial GGE\&H reduction. Indirect GGE\&H reduction, also known as green GGE\&H reduction, reduces greenhouse gases and pollution through sequestration and purification of air, soil, and water by ecosystems such as forests and wetlands.

The "haze satellite map" produced by the NASA in 2013 showed a "Gray Great Wall" in the sky from Beijing to Hong Kong [10-11], indicating serious air pollution and an urgent need to change the development model in China. The Industrial Revolution is being replaced with a "green revolution" and "ecological civilization construction" [12]. Therefore, the roles of industrial measures and ecosystems in greenhouse gas emissions and haze reduction in China need to be clarified. In this review we discuss: 1) issues and difficulties with industrial GGE\&H reduction, 2) the advantages and importance of green GGE\&H reduction, and 3) the future potential of green GGE\&H reduction. Possible approaches to enhance the capability of ecosystems in GGE\&H are highlighted for effectively fighting climate change and air pollution.

\section{Limits of Industrial GGE\&H Reduction}

\section{Issues and Difficulties with Industrial GGE\&H Reduction in China}

In the last several decades, China has undergone rapid industrialization and become the greatest producer of $\mathrm{CO}_{2}$ emissions, which has increased pressure for GGE\&H reduction. In the context of a low-carbon economy, future long-term GGE\&H reduction will pose a serious challenge to China's development [13]. Industrial GGE\&H reduction in China is confronted with growing issues and difficulties: 1) the reduction of energy consumption for enterprises is becoming difficult and room for further GGE\&H reduction is limited, 2) the extensive mode of economic development faces serious challenges, 3) industrial GGE\&H reduction requires high investment and operational costs, 4) the $\mathrm{CO}_{2}$ emissions of per unit GDP is lowered with increasing difficulty, and and 5) high-energy buildings significantly add to energy consumption [14]. The industrial GGE\&H reduction is effective and quick in reducing air pollution, but adds substantial costs. A $20-30 \%$ emission reduction in China would cause $0.7-2.8 \%$ loss in GDP and therefore may result in social instability (e.g., unemployment) and face enormous resistance to implementation of industrial GGE\&H reduction [15].

\section{Costs of Industrial GGE\&H Reduction in Other Countries}

According to the Manchester Guardian, a survey by the European Environment Agency showed that the costs of industrial GGE\&H reduction in air pollution are high in Germany, Poland, and the United Kingdom (UK) [16]. The UK pays £3.4-9.5 billion every year in air pollution for dealing with environment damage and resident health, and $£ 9.5-15.5$ billion each year in coping with $\mathrm{CO}_{2}$ emissions, which is larger than the nation's total investment on culture, the environment, transportation, and intelligence and security.

\section{Advantages and Potential with Green GGE\&H Reduction}

Compared with the industrial GGE\&H reduction, the green GGE\&H reduction requires less investment and operational costs, but offers more ecological benefits and therefore is more economically feasible. The ecological benefits provided by ecosystems (mainly forests and wetlands) are significant to GGE\&H reduction in several ways.

The energy stored in biomass is next to coal, oil, and natural gas. Residues of logging and timber processing in the existing shrubbery (45 million hectares) and firewood (3 million hectares) can provide 330 million tons of biomass each year in China, equivalent to 200 million tons of coal and about $1 / 10$ of the fossil consumption [17].

\section{Carbon Sequestration and Removal of Atmospheric Particulate Matter by Forest Ecosystems}

Forests are the largest carbon reservoirs and the most economical "carbon sequestrationer" on land. China targeted $40-45 \%$ reduction of $\mathrm{CO}_{2}$ emissions per unit GDP from the 2005 level by 2020 at the United Nation (UN) climate conference in Copenhagen in 2009 - much higher than the targets set by the USA (17\%) and the European Union $(30 \%)$. This commitment is mainly dependent on the contribution of forest carbon sequestration. The seventh national forest inventory in China showed that carbon sequestration increased to 359 million tons on 195 million hectares of forests [18]. The $\mathrm{CO}_{2}$ fixation by forests has become an effective way to achieve emission reduction in many countries. The costs to store 1 ton of $\mathrm{CO}_{2}$ through reforestation is approximately $122 \mathrm{RMB}$ [19], which presents a sharp contrast with the cost through industrial GGE\&H reduction (approximately 500RMB). In the last 40 years, the total area of forests in China has increased by 86 million hectares, total forest volume by 5.61 billion $\mathrm{m}^{3}$, total forest carbon sequestration by 206 million tons, and the particulate matter retained in forests by 2.85 billion tons [20]. Moreover, forests are an air purifier, effectively absorbing and removing particulate matter and pollutants from the air at a deposit rate two times greater than that of grass [21]. Compared to grasses, forests have greater surface roughness, which helps reduce wind speed and promote settlement of air particulate matter. The transpiration, respiration, and photosynthesis by forests also help increase air humidity and decrease air temperature, creating a favorable environment for the 
settlement and absorption of air particulate matter [22, 23]. The capacity of forests in air purification is renewed after particles and contaminants on tree leaves are washed away by rain.

Compared to broad-leaved tree species, coniferous trees have rougher crown surfaces and secrete grease and have higher stomata densities, which all help particulate adsorption [21]. Trees also release oxygen, negative air ions, and phytoncide (terpenes) - elements all essential to air quality. The latest findings show that the amount of particulate matter adsorption by forests in China is 5.85 trillion kilogram per year - almost 457 times the 2011 totaldust emissions (127.90 million tons), according to the datafrom the National Statistics Bureau in China.

Despite the difficulties with industrial GGE\&H reduction, China has kept its promise for climate change and air pollution control. According to the eighth national forest inventory in China, the "two increases" for forests proposed at the UN climate change summit in 2009 have gone well. The total area of forests has increased by 24 million hectares from the 2005 level, close to $60 \%$ of the target level for 2020, and the total volume by 1.3 billion $\mathrm{m}^{3}$, already exceeding the target for 2020 . The proportions of young and middle-aged forest area have increase by $65 \%$, which presents a real and forward-looking opportunity for enhancing the potential of GGE\&H reduction by increasing investment and strengthening forest management.

\section{Carbon Sequestration and Removal of Atmospheric Particulate Matter by Wetland Ecosystems}

Wetlands are one of the important carbon sinks in terrestrial ecosystems. Global wetlands account for approximately $6 \%$ of the total land, and $1 / 3$ of the global terrestrial soil carbon pool. The wetlands in China are $40.69 \mathrm{t} / \mathrm{ha}$ in average biomass, and store approximately 970 million tons of carbon [24]. Therefore, the protection of wetlands has significant implications for carbon stocks and climate change mitigation. Peat bogs in particular accumulate a large amount of carbon through anaerobic conditions of water saturation and slow microbe activity and decomposition [25]. Wetlands are also important for removing atmospheric particulate matter through enhanced turbulent transport and gravity in a highmoisture environment. Wetland types, areas, shapes, and plant composition can affect the reduction of atmospheric particles [26]. Comparatively, lake reservoir wetlands have a richer plant composition, larger concentrated area, and longer water evaporation time, and therefore are more effective in atmospheric particle reduction than river wetlands. Based on the monitoring data by the Shaanxi Environmental Protection Bureau, the current wetland ecosystems in Guanzhong can remove 247.6 thousand tons of atmospheric particulate matter per year [27].

Over the past 50 years, the shrinkage of wetlands in China has led to a total loss of $1.5 \mathrm{Gt} \mathrm{C}$, which is equivalent to China's total $\mathrm{CO}_{2}$ emissions in 2006 and close to $1 / 7-1 / 6$ of the total carbon pool of current wetlands.
Therefore, the effective protection of wetlands is crucial to GGE\&H reduction and has profound implications for mitigating global climate change and air pollution. China's government has implemented policies to protect wetlands for ecological security. A total of 180,000 square kilometers wetlands ( $47 \%$ of the total wetlands) are currently under protection, which includes $51.52 \%$ of the key ecological functionareas and $66.52 \%$ of the important national wetlands.More than $1 / 3$ of the wetlands need to be protected andrestored, as the destruction of 1 hectare wetlands can result in a release of 15,000 tons of $\mathrm{CO}_{2}$ into the atmosphere [28]. The measures, such as implementation of lake wetland restoration projects, prohibition of occupation, and reclamation lakes and wetlands will further enhance the capacity of wetland green GGE\&H reduction.

\section{Enhancing Ecosystem Capability in GGE\&H Reduction}

The ecological benefits of forests take a long time to develop (from decades to centuries) and are negatively affected by natural disasters. The resource values of forests in China are low and strongly influenced by forest rights and land ownership systems. New legislation is required to establish new management mechanisms for clear property rights, integrate duty and rights, and secure the stability and certainty of managers and owners with the rights and resources of transactions.

To enhance the contribution of forests and wetlands in GGE\&H reduction, China needs to establish and improve the market price system for natural resources and ecological services, allow market deciding resource allocation, and improve the compensation system for resource use and ecological services so that the resources on farmers' hands can become green wealth. Currently, ecological compensation only services some public forests, although all forests contribute to carbon sequestration and atmospheric environmental purification. According to the principle of "whoever provides benefits should be compensated and whoever destroys them should pay for them," a national and cross-regional ecological compensation system should be established through government purchases and market-based methods based on entirely on ecosystem service values. This compensation system is based on sound scientific standards and gives full consideration to a government's willingness to pay, financial income level, and other factors. The "one size fits all" compensation policy does not consider the differences of ecological services among regional, watershed, and forest types. Therefore, a new resource use and ecological compensation system that reflects market supply and demand, resource scarcity, ecological value, and intergenerational compensation is required to achieve the real purpose of ecological compensation.

To deal with the pressure of resources and environmental issues, a platform should be established under the State Statistics Bureau in China to integrateall 
related government agencies such as environmental protection,land, water conservancy, meteorology, and orestry. This platform is based on consistent, continuousobservations and an inventory of complete forestecosystem services to achieve measurable, quantifiable,describable objectives, provide a database for assessment of ecosystem services, and establish a sound ecological GDP accounting system.

Within each province, forestry investment is not proportional to ecosystem services received. For example, forestry investment in Beijing accounts for 9.52\% and forest ecological benefits for $0.26 \%$ of the GDP, while forestry investment in Heilongjiang, Yunnan, Sichuan, Inner Mongolia, and Guangxi accounts for $22.06 \%$, and forest ecological benefits for $42.13 \%$ of their GDP. A full consideration of ecosystem services will encourage forestry investment on forest cultivation and wetland restoration and protection.

The administration of resource management and ecosystem integrity needs to be reformed. First, trees and other forest resources are divided, with forest land use rights certificates and forest ownership certificates in different government departments of land resource management and forestry. There is a lack of natural connection between different components of forestry resources. Second, ecological compensation funds are laterally transferred. Forests and wetlands provide services, including water conservation, carbon fixation, oxygen release, and air purification. Therefore, forestry departments should also receive appropriate compensation funds to manage forests and wetlands for higher GGE\&H reduction capacity.

In dealing with serious environmental and ecological issues, China should scientifically assess the status and role of forests and wetlands and strengthen forest and wetland resource planning and management to promote multi-level and multi-channel input mechanisms for the cultivation and protection of forests and wetland resources in order to enhance the capacity of forests and wetlands in GGE\&H reduction.

\section{Conclusions}

Compared with industrial GGE\&H reduction, green GGE\&H reduction requires less investment and operational cost, but offers more benefits and therefore is more economically feasible in China. The capacity of forests and wetlands in GGE\&H reduction is enormous and can be further increased through the proper reform of resource management policies.

\section{Acknowledgements}

This work was financially supported by the Fundamental Research Funds for the Central Public Research Institutes (CAFBB2016QA007), the National Natural Science Foundation of China Youth Science Fund Project (31600359), and the grants from the Beijing Municipal
Education Commission (PXM2017 014207 000043). In addition, this paper was supported by CFERN \& BEIJING TECHNO SOLUTIONS Award Funds on excellent academic achievements.

\section{Author Contributions}

Ideas were provided by Xiang Niu, data collection and analysis were done by Bing Wang, and manuscript preparation was done by Wenjun Wei.

\section{Key Messages:}

- Difficulties with industrial GGE\&H reduction.

- Potential roles of green GGE\&H reduction.

- Options to enhance the capacity of green GGE\&H reduction in China.

\section{References}

1. IPCC. Climate Change 2014: Synthesis Report. Contribution of Working Groups I, II and III to the Fifth Assessment Report of the Intergovernmental Panel on Climate Change, PACHAURI R.K., and MEYER L.A. (eds.). IPCC, Geneva, Switzerland, 151 pp. 2014.

2. SCHWARTZ J. Air pollution and daily mortality: a review and meta analysis. Environ Res 64, 36, 1994.

3. DAVIS D. L. A look back at the London smog of 1952 and the half century since. Environ Health Perspect. 110, A734, 2002.

4. JOHNSON R.L. Relative effects of air pollution on lungs and heart. Circulation, 109, 5, 2004.

5. HU B., CHEN R., XU J.X., YANG G.S, XU D.D., CHEN C.Y., ZHAO Y.L. Health effects of ambient ultrafine (nano) particles in haze . Chin Sci Bull 60, 2808, 2015 [In Chinese].

6. MEINSHAUSEN M., MEINSHAUSEN N., HARE W., RAPER S. C., FRIELER K., KNUTTI R., FRAME D. J., ALLEN M. R. Greenhouse-gas emission targets for limiting global warming to $2 \mathrm{C}$. Nature 458, 1158, 2009.

7. MILES L., KAPOS V. Reducing greenhouse gas emissions from deforestation and forest degradation: global land-use implications. Science 320, 1454, 2008.

8. WOODCOCK J., EDWARDS P., TONNE C., ARMSTRONG B. G., ASHIRU O., BANISTER D., BEEVERS S., CHALABI Z., CHOWDHURY Z., COHEN A., FRANCO O.H., HAINES A., HICKMAN R., LINDSAY G., MITTAL I., MOHAN D., TIWARI G., WOODWARD A., ROBERTS I. Public health benefits of strategies to reduce greenhousegas emissions: urban land transport. Lancet 374, 1930, 2009.

9. HAINES A., MCMICHAEL A. J., SMITH K. R., ROBERTS I., WOODCOCK J., MARKANDYA A., ARMSTRONG B.G., CAMPBELL-LENDRUM D., DANGOUR A.D., DAVIES M., BRUC N., TONNE C., BARRETT M., WILKINSON P. Public health benefits of strategies to reduce greenhouse-gas emissions: overview and implications for policy makers. Lancet, 374, 2104, 2010.

10. CHEN B., LU S., LI S., WANG B. Impact of fine particulate fluctuation and other variables on Beijing's air quality index. Environ. Sci Pollution Res 22, 5139, 2015.

11. SUN Y., JIANG Q., WANG Z., FU P., LI J., YANG T., YIN $Y$. Investigation of the sources and evolution processes of severe haze pollution in Beijing in January 2013. J Geophy Res Atmospheres 119, 4380, 2014. 
12. MCCLOSKEY M. In the Thick of It: My Life in the Sierra Club. Island Press, Washington DC, America, 2005.

13. GREGG J.S., ANDRES R.J., MARLAND G. China: Emissions pattern of the world leader in $\mathrm{CO}_{2}$ emissions from fossil fuel consumption and cement production. Geophy Res Letter 35, L08806, 2008.

14. ZHANG Z. Decoupling China's carbon emissions increase from economic growth: An economic analysis and policy implications. World Develop 28, 739, 2000 [In Chinese].

15. ZHANG X.P., CHENG X.M. Energy consumption, carbon emissions, and economic growth in China. Ecol Econ 68, 2706, 2009 [In Chinese].

16. VIDAL J., GERSMANN H. Industrial pollution costs UK billions each year'. Guardian, 2011.

17. LU H.Y. Forest industry should seize the opportunity of "haze economy". Chinese Green Times B02, 2014 [In Chinese].

18. THE PROJECT GROUP OF ASSESSMENT OF FOREST ECOLOGICAL SERVICES IN CHINA. Assessment of forest ecological services in China. China Forestry Publishing House, Beijing, China 2010 [In Chinese].

19. WANG K.D. On measures for promoting forestation's carbon trading in China. China Open J 155, 65, 2011 [In Chinese].

20. PROJECT OF CHINA'S FOREST RESOURCES ACCOUNTING. China's forest resources accounting in the construction of ecological civilization system. Beijing: China Forestry Publishing House, 2015.

21. ZHANG W.K., WANG B., NIU X. Study on the Adsorption Capacities for Airborne Particulates of Landscape Plants in
Different Polluted Regions in Beijing (China). International J Environ Res Public Health 12, 9623, 2015.

22. BECKETT K.P., FREER-SMITH P.H., TAYLOR G. Particulate pollution capture by urban trees: effect of species and windspeed. Global Change Biol 6, 995, 2000.

23. FREER-SMITH P.H., EL-KHATIB A.A., TAYLOR G. Capture of particulate pollution by trees: a comparison of species typiaca of semi-arid areas (Ficus Nitida and Eucalyptus Globulus) with European and north American species. Water Air Soil Pollution 155, 173, 2004.

24. LV Z.M., SHENG L.X., ZHANG L. A review on carbon fluxes for typical wetlands in different climates of china. Wetland Sci 11, 114, 2013.

25. LUND M., LINDROTH A., CHRISTENSEN T.R. Annual $\mathrm{CO}_{2}$ balance of a temperate bog. Tellus B 5959, 804, 2007.

26. CUI L.J., KANG X.M., ZHAO X.S., LI W., MA M.Y., ZHANG M.Y., WEI Y.Y. Spatiotemporal variation in the microclimate effects of typical urban wetland in Beijing. Chin J Ecol 34, 212, 2015.

27. FORESTRY DEPARTMENT OF SHAANXI PROVINCE. The first national evaluation of pollution control and haze reduction function. http//www.shaanxi.gov.cn/0/ xxgk/1/2/4/4 82/2671/2680/2691/430 26.htm. 2014.

28. WETLAND PROTECTION AND MANAGEMENT CENTER OF STATE FORESTRY ADMINISTRATION. Actively restored to expand the wetland area. http://www. forestry.gov.cn/main/4431/content-725238.html. 2014. 
